\title{
Acinetobacter calcoaceticus
}

National Cancer Institute

\section{Source}

National Cancer Institute. Acinetobacter calcoaceticus. NCI Thesaurus. Code C86090.

A species of aerobic, Gram negative, rod and cocci shaped bacteria assigned to the phylum Proteobacteria. This bacteria is nonmotile and oxidase negative. A. calcoaceticus is thought to be a commensal organism of the skin and throat but may become pathogenic in patients with underlying conditions, usually causing respiratory infection. 